\title{
When Children's Knowledge of Memory Improves Children's
}

\section{Performance in Memory}

Marie Geurten, Corinne Catale, \& Thierry Meulemans

Department of Psychology: Cognition and Behavior, Neuropsychology Unit, University of Liège, Belgium

\author{
Marie Geurten \\ Department of Psychology: Cognition and Behavior \\ Neuropsychology Unit \\ University of Liège \\ Boulevard du Rectorat - B33 \\ 4000 Liège \\ BELGIUM \\ mgeurten@ulg.ac.be \\ Phone: +3243665943
}




\begin{abstract}
One of the strongest hypotheses in the field of metacognition research involves the positive effect of metamemory on memory performance. However, due to the lack of appropriate instruments to appraise knowledge of memory, few studies have examined this effect among children. This study was conducted to create and validate an instrument to assess children's metamemory knowledge and link this knowledge with their memory performance and strategy use. A sample of 166 children was given a new three-factor metamemory interview, and its psychometric properties were investigated. Regression analyses were carried out to investigate the link between metamemory and memory performance in a subgroup of 128 children from the validation study. Results confirmed the scale's good psychometric properties and revealed its ability to predict children's memory performance. However, none of the scale's factors could predict children's use of memory strategies. Implications for the study of children's metamemory development are discussed.
\end{abstract}




\section{Introduction}

Imagine a young man in his room, feet on the desk, music playing loudly in his earphones. He is preparing for an exam, well aware that he is not studying at peak efficiency. So, with a little sigh, he sits up straight, mutes the music, and starts to logically organize the key events of the chapter he was reading. Once finished, he asks someone to quiz him. Two days later, he will pass the exam.

This combination of strategic knowledge and regulatory processes working together with the sole aim of improving memory performance is what best describes metamemory.

Traditionally, metamemory is divided into three main components: monitoring, which enables one to judge the quality of learning; control, which verifies recall readiness; and repertoire, which contains knowledge of all the variables that affect memory functioning (Andrés, Mazzoni, \& Howard, 2010; Schneider, 2008; Son \& Metcalfe, 2000). In this study, we will focus on the latter component, the knowledge that led the young man in our example to turn off his sound system in order to reduce interference and choose the right strategy to complete the task he was carrying out.

In adulthood, metamemory repertoire is commonly assessed with self-report measures (Dixon, Hultsch, \& Hertzog, 1988; Troyer \& Rich, 2002). Essentially, subjects are asked to report their knowledge of memory processes - for example, the frequency of strategy use - on a Likert-type scale. These instruments generally demonstrate good psychometric properties and reveal several factors underlying metamemory knowledge (Tonkovic \& Vranic, 2011). These factors are believed to appraise participants' knowledge of (1) their own memory capacities, (2) internal strategies, (3) external strategies, and (4) variables that influence memory performance (Tonkovic \& Vranic, 2011; Troyer \& Rich, 2002). Furthermore, most of these scales have been 
shown to predict memory performance when the type of knowledge investigated is appropriate to the memory task in question (Cavanaugh \& Poon, 1989; Hutchens et al., 2012). For example, in a classical laboratory task where external strategy use (e.g., taking notes, recruiting assistance, etc.) is proscribed whereas internal strategy use (e.g., mental imagery, recapitulation, etc.) is encouraged, the detection of the relationship between metamemory repertoire and memory performance depends on whether or not the knowledge examined in the experiment evaluates mainly internal strategies (Kuhn, 2000).

Nevertheless, in childhood, the situation is different. Because of their poor ability to assess their own competence (Shin, Bjorklund, \& Beck, 2007), self-report evaluations are not suitable to appraise children's metamemory repertoire. Consequently, investigating children's knowledge of variables that influence memory functioning demands a less direct method. Rather than directly ask children - without any contextual information - what strategies they know and how often they use them, Kreutzer, Leonard, and Flavell (1975) chose to confront children (from kindergarten to late elementary school) with a variety of problematic screenplays which, to be solved, required them to search in their metamemory repertoire. Specifically, some scenarios were constructed in such a way that children had to call upon their explicit knowledge of metamemory strategies to answer the questions, while other scenarios required participants to choose one of several alternative responses (forced choice) and justify their answer. In the Story List scenario, for example, children were shown pictures of unrelated objects and asked if it would be easier for them to recall these pictures after hearing their names, or after hearing a story about them. A correct response reflected children's understanding that a story is easier to remember than a list, because it creates links between all the items. Together, these 14 subtests investigate a wide range of areas, such as knowledge of strategies for retrieving the past and 
preparing for the future, knowledge of task demands, and knowledge of how properties of memory storage influence retrieval.

However, although the interview created by Kreutzer et al. (1975) has been demonstrated to provide privileged access to children's metamemory repertoire (Belmont \& Borkowski, 1988; Lockl \& Schneider, 2007), it has also been shown to be affected by certain psychometric weaknesses, the most important of which is the absence of any clear relation between the subtests of the scale (Fritz, Howie, \& Kleitman, 2010). Even the selection of the subtests claimed to be the most valid and sensitive indicators of children's metamemory knowledge (i.e., Story List, Preparation Object, Retrieval Event, Immediate Delay, Retroactive Interference, and Rote Paraphrase) has demonstrated poor internal consistency and a strong tendency to underestimate young children's metacognitive skills (Kurtz, Reid, Borkowski, \& Cavanaugh, 1982). Nevertheless, most researchers agree that metamemory knowledge starts to develop at a very young age and that this early development is followed by continued refinement through adolescence (for an overview, see Schneider, 2008). In support of this claim, Johnson and Wellman (1980) demonstrated that children as young as 3.5 years old could engage in some rudimentary verbalization about their memory functioning and use appropriate mental verbs (e.g., forget, remember, know, guess, etc.) to describe the quality of their learning (see also Cherney, 2003). Similarly, Schneider (2008) reported that the influence of list length on memory performance is understood as early as 4 years old. More specifically, the results of the latter study revealed that even very young children were able to correctly decide that people who have studied only 3 items will remember them better than people who have studied 9 or 18 items.

On the other hand, using an abbreviated Kreutzer et al. (1975) interview that included the six most sensitive subtests of the original battery, Fritz et al. (2010) found that 6-year-old 
children did not score statistically above chance for most of the subtests that composed the scale (i.e., Story List, Retrieval Event, Immediate Delay, and Retroactive Interference). Yet, according to Schneider (2008) and Johnson and Wellman (1980), children of this age should have demonstrated basic knowledge of their memory functioning. According to Fritz et al. (2010), there are two main explanations for the interview's lack of reliability and sensitivity: (1) the exclusively oral presentation of the screenplays, which seems to make considerable demands on both short-term memory and language abilities; and (2) the presence of underlying factors within the scale. Indeed, if the subtests of the interview do not all appraise the same category of metamemory knowledge, the poor inter-item reliability is not surprising. Moreover, this limitation probably explains why a link between children's metamemory repertoire and memory performance has rarely been noted in developmental studies (Mecklenbrauker, 1988; Van der Keilen \& Zhou, 2006).

As mentioned above, the effect of metamemory on adults' memory performance has principally been shown when the categories of knowledge investigated were appropriate to the task administered in the study (Cavanaugh \& Poon, 1989; Hutchens et al., 2012). But, if the factor structure of the metamemory interview could be identified, the same instrument could be used to investigate the influence of different categories of knowledge on various memory tasks without losing predictive power. Furthermore, such a tool would be much more appropriate and interesting to study the development of metamemory knowledge or highlight links with certain specific aspects of general cognitive functioning.

In this context, we decided to create and test a metamemory scale for French-speaking children. Inspired by Kreutzer et al.'s (1975) interview, this adjusted scale was designed to improve the psychometric weaknesses usually demonstrated by children's metamemory 
measures, as its rating system should allow inspection of the factor structure. More specifically, we hypothesized that a three-factor structure would emerge from the five subtests selected to create the French-adapted metamemory scale. According to Fritz et al.'s (2010) exploratory analysis, the chosen screenplays form only two factors: a first factor composed of subtests that involve general knowledge of memory functioning (e.g., delay or interference effects) and a second factor comprising subtests that require strategy generation. Nonetheless, the way children's responses are recorded in Fritz et al.'s version of the instrument - one score per scenario - does not permit one to investigate components of a screenplay. Yet this has important implications. With this scoring method, the traditional distinction between internal and external strategy knowledge (Bouazzaoui et al., 2010; Intons-Peterson \& Fournier, 1986; Schryer \& Ross, 2013) cannot be tested because both internal and external strategies are generated to perform the same subtest. Consequently, the fact that Fritz et al.'s exploratory analysis was not able to dissociate these two categories of knowledge is understandable, as is the fact that the total variance explained by their two-factor model remains relatively low. In contrast, we employed a rating system developed not only to appraise a general memory functioning factor, but also to distinguish between external and internal strategy knowledge.

\section{This Study}

The present study was divided into two phases. In the first phase, the psychometric properties of the scale - specifically, its ability to differentiate between the youngest groups of children - and the relevance of the three-factor model were examined. Then, in the second phase, the new scale's predictive validity was investigated by exploring each subscale's contribution to memory performance. Specifically, given the clustering-memory task administered in the experiment, we assumed that, of the three factors, internal strategy would be the most powerful 
predictor of memory performance. In addition, we also chose to examine the scale's ability to predict children's strategy use. The most common hypothesis explaining the influence of metamemory knowledge on memory performance involves strategy utilization. A child who uses suitable strategies during a memory task will perform better than one who does not (Coyle \& Bjorklund, 1997; McDougall \& Gruneberg, 2002; Pierce \& Lange, 2000). Similarly, the likelihood that children will actually use certain strategies increases proportionally to the knowledge they have of them (DeMarie \& Ferron, 2003). In this context, demonstrating the contribution of the French-adapted metamemory instrument to children's use of memory strategies would provide an interesting argument supporting the good predictive validity of the scale.

\section{Study 1}

\section{Method}

Participants. A total of 166 typically developing unilingual children whose ages ranged from 43 months to 149 months (Mean $=95.04, \mathrm{SD}=32.14$ ) participated in this study. Fifty-one percent of the subjects were girls. No participants were excluded from our analyses. The mean of both parents' years of education was used to appraise socioeconomic status (Mean $=14.48, \mathrm{SD}=$ 2.17) and standard scores on the Matrix subtest of the Wechsler Intelligence Scale for Children (WISC-IV; Wechsler, 2005) and of the Wechsler Preschool and Primary Scale of Intelligence (WPPSI-III; Wechsler, 2004) were used to evaluate nonverbal intelligence (Mean $=11.21, \mathrm{SD}=$ 2.71). The sample was recruited from French-speaking kindergartens and elementary schools in the province of Liège, Belgium.

\section{Materials.}


Peabody Picture Vocabulary Test. The French version of the Peabody Picture Vocabulary Test (PPVT-R; Dunn, Thériault-Whalen, \& Dunn, 1993) is a measure of receptive vocabulary that requires children to choose which of four pictures best illustrates a word. The raw score is calculated by subtracting from the ceiling item (last item administered) the total number of errors made after the basal item (eighth item in a row answered correctly).

Metamemory scale. Five subtests inspired by Kreutzer et al.'s (1975) interview were used as cornerstones of this new metamemory measure. These five subtests (Preparation Object, Retrieval Event, Immediate Delay, Retroactive Interference, and Rote Paraphrase) - known to be some of the most valid, sensitive indicators of metamemory knowledge in children (Kurtz et al., 1982) - were adapted for French-speaking children and modified to mitigate their three main psychometric weaknesses: (1) subordination to linguistic skills, (2) insufficient developmental sensitivity for young children, and (3) presence of unexplored underlying factors (Fritz et al., 2010).

Essentially, participants were presented with a variety of screenplays and, depending on the scenario, were asked either to list as many relevant strategies as possible (e.g., "Could you give me all the ways that you could solve this problem?") or to select one of two alternative responses (e.g., "What would be better, choice X or choice Y?") and justify their answer (e.g., “Why do you think choice X would be better than choice Y?"). Importantly, when children had to select one of two alternative responses, they were obliged to answer (forced choice). Before the test started, a practice screenplay was administered to the children to ensure that they understood the instructions. Compared with the English versions of the scale, the length of the screenplays and the vocabulary used to describe them to participants were simplified, some of the situations presented in the scenario were revised so they were easier for European children to 
understand, and illustrations were provided for each scene in order to lighten participants' memory workload. The aim of these modifications was to reduce contamination by linguistic ability and to overcome the lack of developmental sensitivity demonstrated by previous versions of the instrument. Likewise, adjustments were made to allow for a better exploration of the scale's factor structure. As has often been demonstrated in recent decades, metamemory knowledge is not a unitary construct (Hertzog, Dixon, Schulenberg, \& Hultsch, 1987; Tonkovic \& Vranic, 2011). More specifically, the use of three components of metamemory knowledge seems to be required to solve the problems presented in the five screenplays composing this version of the scale: knowledge of internal strategy, knowledge of external strategy, and knowledge of general memory functioning. The major issue is the fact that all these components are involved in the same subtest. Consequently, the way children's responses were recorded in the previous versions of the instrument - a single score for each subtest - had to be adapted. Thus, for each screenplay, separate scores were calculated each time internal strategy, external strategy, or general memory functioning answers were provided. Ten scores were obtained for the five subtests. Details of screenplays and scoring criteria are given in Table 1.

$<$ Table 1 about here>

Procedure. Parents' and school principals' consent was obtained before the study started. Children were tested individually in a quiet room at their school. Each child participated in a single 45- to 60-minute session, at which the Matrix subtest, the metamemory scale, and the PPVT-R were administered. Participants were allowed to take breaks ( 2 min) between each of the experimental tasks. The order of the tests was counterbalanced within sessions. Analyses indicated no effect of presentation order on performance of any of the tests. Children's answers 
to the metamemory interview were recorded to allow a second independent rater to score them later.

\section{Results}

Data analyses. All statistical analyses were done using LISREL 8.80 and IBM SPSS Statistics 20. The primary focus of this study was to examine the psychometric properties of the French-adapted metamemory scale. For this purpose, the three-factor structure of the instrument was investigated using a confirmatory factor analysis (CFA). This CFA was carried out for the whole sample as well as separately for the younger and the older children in the sample. Several goodness-of-fit indices were used to evaluate the model's acceptability: the $\chi^{2}$ divided by degrees of freedom $\left(\chi^{2} / \mathrm{df}\right)$, the root mean square error of approximation (RMSEA), the comparative fit index (CFI), the non-normed fit index (NNFI), and the standardized root mean square residual (SRMR). To indicate an adequate fit, the $\chi^{2} / \mathrm{df}$ ratio had to be less than 2 , the RMSEA .08 or lower, the CFI and NNFI higher than .95, and the SRMR not above .10 (Brown, 2006). Once the factor structure was supported, internal and inter-rater reliability were inspected using, respectively, Cronbach's $\alpha$ and Cohen's kappa. Spearman correlations were carried out to check speech ability's influence on all 10 items of the scale. Finally, post hoc Tukey's tests were conducted to examine the scale's capacity to distinguish between age groups.

Confirmatory factor analysis and reliability. The hypothesized three-factor model was examined with CFA. The model was tested using a covariance matrix and estimated with the robust maximum likelihood method. Factor loadings for items are summarized in Table 2. The results revealed a $\chi^{2} / \mathrm{df}$ ratio $=1.77, \mathrm{RMSEA}=.06, \mathrm{CFI}=.99, \mathrm{NNFI}=.98$, and $\mathrm{SRMR}=.09$. All of these indices showed an acceptable fit for the model tested. The internal reliability coefficient (Cronbach's $\alpha$ ) was .84 for the whole scale and .72, .74 and .58, respectively, for the internal 
strategy, external strategy and general memory functioning factors. These scores indicated good internal reliability for the three higher values and poor reliability for the lowest value (Schmitt, 1996).

A measure of agreement between independent raters was also calculated for every item of the scale. Cohen's kappa correlations ranged from .72 to .91 , which suggested substantial to almost perfect agreement.

\section{$<$ Table 2 about here>}

Finally, the developmental stability of the factor structure was also investigated. Specifically, separate CFA were conducted with the younger $(n=89$; from 4 to 7 years old $)$ and the older ( $\mathrm{n}=77$; from 8 to 12 years old) children in the sample. The results showed a $\chi^{2} / \mathrm{df}$ ratio $=1.18, \mathrm{RMSEA}=.05, \mathrm{CFI}=.95$, and $\mathrm{SRMR}=.06$ for the younger group, and a $\chi^{2} / \mathrm{df}$ ratio $=$ $1.29, \mathrm{RMSEA}=.06, \mathrm{CFI}=.69$, and SRMR $=.07$ for the older group. Except for the CFI for the oldest children, all of these indices showed an acceptable fit for the model tested.

Vocabulary influence. Table 3 shows the Spearman correlations between all the items of the French metamemory scale and the standard score on the PPVT-R. As expected, most of the correlations were around zero. Only the relation between the PPVT-R and the item labeled "IDGeneral" of the Immediate Delay screenplay reached significance $(r=.19, p=.01)$. These results seem to confirm the relevance of the adjustments made to buffer the scale from contamination by language skill.

$<$ Table 3 about here>

Age effect. A one-way analysis of variance (ANOVA) was conducted to determine whether - with a particular focus on the youngest children - the developmental sensitivity of the French metamemory scale was sufficient to detect a distinction between the metamemory 
knowledge of children aged 4-5 $(n=44), 6-7(n=44), 8-10(n=44)$, and 11-12 $(n=34)$. The number of participants aged 7, 8, 10, and 12 years old was too small to conduct the analyses for each age separately. The results indicated significant main effects of age group on the global scale $\left(F(4,162)=28.66, p<.001, \eta^{2}=.76\right)$, as well as on the internal strategy $(F(4,162)=45.29$, $\left.p<.001, \eta^{2}=.63\right)$, external strategy $\left(F(4,162)=31.77, p<.001, \eta^{2}=.54\right)$, and general memory functioning factors $\left(F(4,162)=28.29, p<.001, \eta^{2}=.55\right)$. Post hoc analyses (Tukey's test) highlighted a significant difference between all age groups for every dependent variable $(p<$ .05). Except the two older groups, which did not differ from one another on the general memory functioning factor $(p=.21)$, the results consistently showed that older groups of children obtained higher scores than younger ones.

\section{Study 2}

\section{Method}

Participants. Participants were 128 typically developing children aged 4, 6, 9, and 11 years old drawn from study 1 so as to obtain a balanced 4 (Age Group) x 2 (Sex) x 2 (Order) experimental design. There were 32 participants per groups (16 girls). The groups were strictly equivalent in terms of socioeconomic status $(F(3,126)=0.43, p=.73)$ and nonverbal intelligence $(F(3,126)=1.79, p=.15)$. As mentioned above, the mean of both parents' years of education was used to appraise socioeconomic status, while standard scores on the Matrix subtest (Wechsler, 2004, 2005) were used to evaluate nonverbal intelligence.

Materials and procedure. Children were given a clustering-recall task inspired by the classical California Verbal Learning Test (CVLT; Delis, Freeland, Kramer, \& Kaplan, 1988) and modified to be accessible to children as young as 4 and usable in our sample without demonstrating ceiling effects. Specifically, a list composed of 12 words from three different 
categories (Clothes; Games; Furniture) was orally presented (reading) to each child at a rate of one word every second in a pseudo-random manner - that is, words were presented arbitrarily but in the same order for each child and over each trial. Subjects were asked to listen to the 12word list presented over four trials, and were then instructed to perform free and cued recall tasks, after short (2-minute) and long (20-minute) delays. In free recall tests, participants were required to recall as many words as possible from the list (e.g., "Tell me - in no particular order - all the words that you can remember from the list."). Conversely, in cued recall tests, participants were instructed to recall words depending on the semantic category to which they belong (e.g., "There were some clothes in the list. Tell me all the clothes that you can remember from the list."). When children produced words that were not part of the 12-word list, they were directly informed of their error.

In this experiment, participants' scores for the two free recall tests were highly correlated $(\mathrm{r}=.83)$, as were their scores for the two cued recall tests $(r=.93)$. In this context, the number of correct words for free recalls (short and long delays) and the number of correct words for cued recalls (short and long delays) were standardized and averaged, respectively, to form two separate composite scores labeled (1) Recall (Free) and (2) Recall (Cued). Following the procedure developed by Roenker, Thompson, and Brown (1971) to appraise children's ability to strategically organize their memory behaviors, two adjusted clustering ratios (ARC) were also computed: (1) a semantic clustering ratio, which represents children's tendency to use a categorical organization at recall; and (2) a serial clustering ratio, which represents children's tendency to recall words in the same order as presented. As the nature of the cued recall tests required children to recall words using an imposed semantic clustering, the two ARC indexes should logically not be calculated for these tests (Delis et al., 1988). Consequently, the ARC 
indexes used in this experiment were computed on the basis of children's semantic and serial clustering for the free recall tasks.

As mentioned in the previous section, each child participated in a single 60-minute session, at which the Matrix subtest, the metamemory scale, and the PPVT-R were also administered. The order of the tests was counterbalanced within sessions. Once again, the analyses indicated no effect of presentation order on performance of any of the tests, proving that children's performance was the same, whether the tasks were completed at the beginning or the end of the session.

\section{Results}

Data analyses. All statistical analyses were calculated using IBM SPSS Statistics 20. The primary goal of this study was to examine the ability of the French-adapted metamemory scale to predict memory performance and memory strategy use. For this purpose, several multiple regression analyses were carried out. The variables included in the analyses were (1) the score computed for the whole metamemory scale, (2) the scores computed for each of the three metamemory factors (i.e., internal strategy knowledge, external strategy knowledge, and general knowledge), and (3) the two ARC indexes. The influence of children's chronological age (months) was also taken into account in each of the seven regressions. Table 4 shows children's scores for each of these variables displayed by age group.

$<$ Table 4 above here>

Memory performance and metamemory knowledge. One of the main theories in the field of metamemory research is that metamemory knowledge has a positive effect on memory performance. Thus, if the French-adapted scale is truly an appropriate measure of metamemory, a link should be found between the total score on the scale - or some of the factor scores - and 
the number of words recalled in the memory task. To examine this prediction, two regression analyses were carried out for each of the two composite memory scores. The first regression aimed to demonstrate the whole scale's ability to predict memory performance at free and cued recall, whereas the second regression was conducted to determine which exact metamemory components were involved in this performance. As can be seen in Table 5, the results showed that the total score for the metamemory scale contributed to the unique variance of memory performance for free $\left(\beta=.30, p=.002, \mathrm{R}^{2}=.07\right)$ and cued recall $\left(\beta=.27, p=.005, \mathrm{R}^{2}=.06\right)$. Moreover, analyses conducted to highlight the specific influence of each factor on children's memory revealed that the composite score for free recall was predicted by chronological age $(\beta=$ $\left..49, p<.001, \mathrm{R}^{2}=.52\right)$, and internal strategy knowledge $\left(\beta=.17, p=.04, \mathrm{R}^{2}=.04\right)$. The same tendency was observed for the cued composite score, except that the effect of internal strategy knowledge did not reach significance $\left(\beta=.14, p=.08, \mathrm{R}^{2}=.03\right)$.

$<$ Table 5 above here $>$

Knowledge, memory, and strategy use. The most common hypothesis explaining the influence of metamemory knowledge on memory performance involves strategy utilization. A child who employs one or more suitable strategies during a memory task will perform better than one who does not (McDougall \& Gruneberg, 2002; Pierce \& Lange, 2000). Similarly, the likelihood that children will apply certain strategies increases proportionally to their knowledge of them (DeMarie \& Ferron, 2003). In this study, the influence of internal strategy knowledge on memory performance had already been demonstrated. Now, we examined the mechanisms underlying this influence. Three regressions were conducted (1) to confirm the positive link between strategy utilization and memory score, and (2) to highlight the effect of internal strategy knowledge on strategy use. Adjusted semantic and serial clustering ratios were used as measures 
of strategy utilization and the free recall composite score - the only one on which the effect of internal strategy reached significance - was used as a measure of memory functioning. As can be seen in Table 5, the results revealed that semantic - but not serial - clustering contributed significantly to the unique amount of variance explained at free recall $\left(\beta=.13, p=.04, \mathrm{R}^{2}=.03\right)$. Nevertheless, internal strategy knowledge failed to predict children's use of these two organized strategies ( $p=.94$ and .41 , for semantic and serial clustering, respectively).

\section{General Discussion}

The assumption that knowledge about memory functioning has a positive effect on memory recall is one of the founding principles in the field of metamemory research. However, this link has rarely been demonstrated in children due to the lack of valid instruments to appraise their metamemory knowledge (Mecklenbrauker, 1988; Van der Keilen \& Zhou, 2006). In this context, the present study was conducted to examine the psychometric properties of a Frenchadapted version of Kreutzer et al.'s (1975) metamemory interview for children. Specifically, factor structure, developmental sensitivity, internal consistency, and inter-rater reliability were investigated.

The hypothesized three-factor model of the scale was confirmed and the developmental stability of the factor structure was established. For the first time - and importantly for the study of children's metamemory - the presence of hidden factors within the metamemory interview's screenplays was highlighted, even in children younger than 8 . Until now, even though the multiplicity of metamemory knowledge components was commonly accepted in studies of adults (Hertzog et al., 1987; Tonkovic \& Vranic, 2011), children's metamemory repertoire was generally considered to be a unitary construct and some studies in children did not even find sufficient support for a single metamemory factor before the age of 9 (e.g., DeMarie \& Ferron, 
2003). Consequently, over time and across studies, different kinds of knowledge were used without distinction, and inconsistent results were therefore obtained (Geddie, Fradin, \& Beer, 2000; Mecklenbrauker, 1988). Consequently, our knowledge of children's memory understanding remained quite low. Thus, the three-factor scale validated in this experiment should be a helpful tool for investigating metamemory development throughout childhood, particularly as it was shown to be less dependent on language abilities and revealed good reliability (internal consistency and inter-rater agreement) and developmental sensitivity. Furthermore, the scale's predictive validity was also partly established. Although the effect size was moderate at best, a link was found between the metamemory scale, its internal strategy factor, and memory performance, demonstrating the instrument's ability to examine the relationships between metamemory and other areas of cognitive functioning.

Nevertheless, this study did produce an unforeseen result. According to many authors (DeMarie, Miller, Ferron, \& Cunningham, 2004; Grammer, Purtell, Coffman, \& Ornstein, 2011), the effect of metamemory knowledge on memory performance is - at least partially - mediated by strategy use. But, in our experiment, no relationship was found between the internal strategy factor and the strategy use index. At first sight, these results seem to indicate that the children's strategy repertoire is involved in memory recall regardless of whether or not they actually use these strategies. However, we reject this unconvincing assumption for two reasons.

First, although semantic clustering is the best method - in adulthood anyway - for completing a task such as the one administered in this experiment (Alexander, Stuss, \& Fansabedian, 2003), it is definitely not the only available one. Other strategies - specific to each child - can be employed to improve performance (Coyle \& Bjorklund, 1997; Hutchens et al., 2012). For example, some studies demonstrate that children are perfectly well able to elaborate 
semantic and perceptual associations between the items to be studied to improve their recall (Bjorklund, Dukes, \& Brown, 2009). Inherently, these subjective strategies (e.g., personal word associations, mental imagery, rehearsal, etc.) - or a combination of these strategies - are probably a better reflection of children's internal strategy repertoire than semantic clustering. Indeed, according to some authors, multiple strategy use is quite common as children develop, and children's memory performance is positively related to this multiplicity of strategies (Coyle, 2001; Coyle \& Bjorklund, 1997). In this context, considering the use of these strategies as the missing link between strategy knowledge and memory performance would not appear to be totally unfounded.

The second element that could explain the lack of relationship between strategy knowledge and utilization concerns how strategy use indexes are computed. Traditionally, the number of clusters - whatever the type of clustering - produced by a participant is assessed without including retold items (Delis et al., 1988; Roenker et al., 1971). Incidentally, this rating system supposes that children begin using strategic processes from the very start of each recall. This may be believed if clustering is considered to be implicit - if children are assumed to associate words unconsciously - but, at the intentional level, the hypothesis that children show strategic behaviors only later in the trial is probably more judicious. Logically, it is possible that participants start to feel a need to apply a strategy only after recalling the words they can remember with ease. But repeated items are not taken into account when the ARC index is calculated. Thus, if children use an already recalled word to conduct a semantic search in memory and, as a result, retrieve an extra word from the list, the association between these items will not be included in the clustering score, which will therefore be underestimated. In this context, the lack of effect of metamemory knowledge on strategy use can be easily understood. 
The metamemory scale adapted in this study assesses children's explicit knowledge of memory functioning. If the clustering index systematically undervalues late strategy use, then it means that this index mainly reflects children's early - and so possibly unintentional - strategy utilization. Consequently, the small correlation between the strategy knowledge and strategy use constructs should probably not be interpreted as indicating the absence of a relationship but rather as a trail to further explore the hypothesis that children may know and use strategies they can neither express verbally nor employ voluntarily.

In conclusion, this study demonstrated the good psychometric properties of the Frenchadapted metamemory scale and confirmed the factor structure of this new instrument. Moreover, the three-factor scale was found to be a useful and reliable tool for investigating children's metamemory repertoire development. Of course, further validation studies must still be conducted to demonstrate the predictive validity of the external strategy and general memory functioning factors and highlight the link between strategy knowledge and strategy use, which could possibly be carried out by assessing children's use of other sorts of memory strategies (e.g., rehearsal, self-testing, personal elaboration, etc.). Nevertheless, despite these limitations, the instrument is able to detect the effect of metamemory knowledge on memory performance, which could lead to new perspectives for research in the field of rehabilitation of children with memory disorders. In addition, interesting prospects have been opened up for the future investigation of implicit metamemory knowledge. Specifically, the hypothesis that children could behaviorally demonstrate some strategic metamemory knowledge that they cannot express verbally would be interesting to explore. 
Page 21

\section{Acknowledgment}

This research was supported by the Belgian Fund for Scientific Research (F.R.S.-FNRS). 


\section{References}

Alexander, M. P., Stuss, D. T., \& Fansabedian, N. (2003). California Verbal Learning Test: Performance by patients with focal frontal and non-frontal lesions. Brain, 126, 14931503. doi:10.1093/brain/awg128

Andrés, P., Mazzoni, G., \& Howard, C. E. (2010). Preserved monitoring and control processes in temporal lobe epilepsy. Neuropsychology, 24, 775-786. doi:10.1037/a0020281

Belmont, J. M., \& Borkowski, J. G. (1988). A group-administered test of children's metamemory. Bulletin of the Psychonomic Society, 26, 206-208.

Bjorklund, D. F., Dukes, C., \& Brown, R. D. (2009). The development of memory strategies. In M. L. C. N. Cowan (Ed.), The development of memory in infancy and childhood (2nd ed.) (pp. 145-175). New York: Psychology Press.

Bouazzaoui, B., Isingrini, M., Fay, S., Angel, L., Vanneste, S., Clarys, D., \& Taconnat, L. (2010). Aging and self-reported internal and external memory strategy uses: The role of executive functioning. Acta Psychologica, 135, 59-66.

doi:http://dx.doi.org/10.1016/j.actpsy.2010.05.007

Brown, T. A. (2006). Confirmatory factor analysis for applied research. New York: Guilford Press.

Cavanaugh, J. C., \& Poon, L. W. (1989). Metamemorial predictors of memory performance in young and older adults. Psychology and Aging, 4, 365-368. doi:http://dx.doi.org/10.1037/0882-7974.4.3.365

Cherney, I. D. (2003). Young children's spontaneous utterances of mental terms and the accuracy of their memory behaviors: A different methodological approach. Infant and Child Development, 12, 89-105. 
Coyle, T. R. (2001). Factor analysis of variability measures in eight independent samples of children and adults. Journal of Experimental Child Psychology, 78, 330-358.

Coyle, T. R., \& Bjorklund, D. F. (1997). Age differences in, and consequences of, multiple- and variable-strategy use on a multitrial sort-recall task. Developmental Psychology, 33, 372380.

Delis, D. C., Freeland, J., Kramer, J. H., \& Kaplan, E. (1988). Integrating clinical assessment with cognitive neuroscience: Construct validation of the California Verbal Learning Test. Journal of Consulting and Clinical Psychology, 56, 123-130. doi:10.1037/0022006X.56.1.123

DeMarie, D., \& Ferron, J. (2003). Capacity, strategies, and metamemory: Tests of a three-factor model of memory development. Journal of Experimental Child Psychology, 84, 167-193.

DeMarie, D., Miller, P. H., Ferron, J., \& Cunningham, W. R. (2004). Path Analysis Tests of Theoretical Models of Children's Memory Performance. Journal of Cognition and Development, 5, 461-492. doi: 10.1207/s15327647jcd0504_4

Dixon, R. A., Hultsch, D. F., \& Hertzog, C. (1988). The Metamemory in Adulthood (MIA) questionnaire. Psychopharmacology Bulletin, 24, 671-688.

Dunn, L., Thériault-Whalen, C., \& Dunn, L. (1993). Echelle de vocabulaire en images Peabody: adaptation française du Peabody vocabulary test - revised. Toronto, ON: Psycan.

Fritz, K., Howie, P., \& Kleitman, S. (2010). “How do I remember when I got my dog?” The structure and development of children's metamemory. Metacognition and Learning, 5, 207-228. doi:http://dx.doi.org/10.1007/s11409-010-9058-0 
Geddie, L., Fradin, S., \& Beer, J. (2000). Child characteristics which impact accuracy of recall and suggestibility in preschoolers: Is age the best predictor? Child Abuse and Neglect, 24, 223-235. doi:http://dx.doi.org/10.1016/S0145-2134(99)00133-7

Grammer, J. K., Purtell, K. M., Coffman, J. L., \& Ornstein, P. A. (2011). Relations between children's metamemory and strategic performance: Time-varying covariates in early elementary school. Journal of Experimental Child Psychology, 108, 139-155. doi:http://dx.doi.org/10.1016/j.jecp.2010.08.001

Hertzog, C., Dixon, R. A., Schulenberg, J. E., \& Hultsch, D. F. (1987). On the differentiation of memory beliefs from memory knowledge: The factor structure of the Metamemory in Adulthood scale. Experimental Aging Research, 13, 101-107. doi:http://dx.doi.org/10.1080/03610738708259308

Hutchens, R. L., Kinsella, G. J., Ong, B., Pike, K. E., Parsons, S., Storey, E., ... Clare, L. (2012). Knowledge and use of memory strategies in amnestic mild cognitive impairment. Psychology and Aging, 27, 768-777. doi:http://dx.doi.org/10.1037/a0026256

Intons-Peterson, M. J., \& Fournier, J. (1986). External and internal memory aids: When and how often do we use them? Journal of Experimental Psychology: General, 115, 267-280. doi:http://dx.doi.org/10.1037/0096-3445.115.3.267

Johnson, C. N., \& Wellman, H. M. (1980). Children's developing understanding of mental verbs: Remember, know, and guess. Child Development, 51, 1095-1102. doi:10.2307/1129549

Kreutzer, M. A., Leonard, C., \& Flavell, J. H. (1975). An interview study of children's knowledge about memory. Monographs of the Society for Research in Child Development, 40, 1-60. doi:http://dx.doi.org/10.2307/1165955 
Kuhn, D. (2000). Metacognitive development. Current Directions in Psychological Science, 9, 178-181. doi:10.1111/1467-8721.00088

Kurtz, B. E., Reid, M. K., Borkowski, J. G., \& Cavanaugh, J. C. (1982). On the reliability and validity of children's metamemory. Bulletin of the Psychonomic Society, 19, 137-140.

Lockl, K., \& Schneider, W. (2007). Knowledge about the mind: Links between theory of mind and later metamemory. Child Development, 78, 148-167. doi:10.1111/j.14678624.2007.00990.x

McDougall, S., \& Gruneberg, M. (2002). What memory strategy is best for examinations in psychology? Applied Cognitive Psychology, 16, 451-458. doi:10.1002/acp.800

Mecklenbrauker, S. (1988). Metamemory-memory connections and their development under imaginal encoding conditions. In M. Denis, J. Engelkamp, \& J. Richardson (Eds.), Cognitive and neuropsychological approaches to mental imagery (pp. 143-152). Dordrecht, Netherlands: Martinus Nijhoff Publishing.

Pierce, S. H., \& Lange, G. (2000). Relationships among metamemory, motivation and memory performance in young school-age children. British Journal of Developmental Psychology, 18, 121-135. doi:10.1348/026151000165616

Roenker, D. L., Thompson, C. P., \& Brown, S. C. (1971). Comparison of measures for the estimation of clustering in free recall. Psychological Bulletin, 76, 45-48. doi:10.1037/h0031355

Schmitt, N. (1996). Uses and abuses of coefficient alpha. Psychological Assessment, 8, 350-353. doi:10.1037/1040-3590.8.4.350 
Schneider, W. (2008). The development of metacognitive knowledge in children and adolescents: Major trends and implications for education. Mind, Brain, and Education, 2, 114-121. doi:10.1111/j.1751-228X.2008.00041.x

Schryer, E., \& Ross, M. (2013). The use and benefits of external memory aids in older and younger adults. Applied Cognitive Psychology, 27, 663-671. doi:10.1002/acp.2946

Shin, H., Bjorklund, D. F., \& Beck, E. F. (2007). The adaptive nature of children's overestimation in a strategic memory task. Cognitive Development, 22, 197-212. doi:http://dx.doi.org/10.1016/j.cogdev.2006.10.001

Son, L. K., \& Metcalfe, J. (2000). Metacognitive and control strategies in study-time allocation. Journal of Experimental Psychology: Learning, Memory, and Cognition, 26, 204-221. doi:http://dx.doi.org/10.1037/0278-7393.26.1.204

Tonkovic, M., \& Vranic, A. (2011). Self-evaluation of memory systems: Development of the questionnaire. Aging and Mental Health, 15, 830-837. doi:http://dx.doi.org/10.1080/13607863.2011.569483

Troyer, A. K., \& Rich, J. B. (2002). Psychometric properties of a new metamemory questionnaire for older adults. The Journals of Gerontology Series B: Psychological Sciences and Social Sciences, 57, 19-27. doi:10.1093/geronb/57.1.P19

Van der Keilen, M., \& Zhou, R.-M. (2006). Metamemory and memory performance in Belgian and Canadian elementary school children: A comparative study. Journal of Cognitive Education and Psychology, 5, 251-265.

doi:http://dx.doi.org/10.1891/194589506787382413

Wechsler, D. (2004). Echelle d'intelligence de Wechsler pour la période préscolaire et primaire: WPPSI-III. Paris: ECPA. 
Page 27

Wechsler, D. (2005). Echelle d'intelligence de Wechsler pour enfants: WISC-IV. Paris: ECPA. 
Page 28

\section{Table 1}

Details of the Metamemory Scale

\begin{tabular}{|c|c|c|c|}
\hline Screenplays & $\begin{array}{l}\text { Number of } \\
\text { illustrations }\end{array}$ & Allowable responses & Scoring \\
\hline Preparation object (PO) & & Handle the ball & General - / \\
\hline $\begin{array}{l}\text { You have to bring a ball to school tomorrow so } \\
\text { you can play with your friends. What could you do } \\
\text { so you won't forget to take it with you when you } \\
\text { leave for school tomorrow morning? }\end{array}$ & 1 & $\begin{array}{l}\text { Write a note } \\
\text { Recruit human assistance } \\
\text { Use internal facilitation }\end{array}$ & $\begin{array}{c}\text { Internal strategy }- \text { MAX }=1 \\
\text { External strategy }- \text { MAX }= \\
3\end{array}$ \\
\hline $\begin{array}{l}\text { Imagine you are a treasure hunter and you have } \\
\text { found a chest. But this chest is locked and only a } \\
\text { code will unlock it. This code is " } 4729 . \text {." What do } \\
\text { you do first? Unlock the chest or take a minute to } \\
\text { drink some water before that? Why? What could } \\
\text { you do to remember a long set of numbers? }\end{array}$ & 3 & $\begin{array}{l}\text { Open the chest first } \\
\text { Not forget the code } \\
\text { Rehearse/Write a note }\end{array}$ & $\begin{array}{c}\text { General }-\mathrm{MAX}=2 \\
\text { Internal strategy }-\mathrm{MAX}=1 \\
\text { External strategy }- \text { MAX = } \\
1\end{array}$ \\
\hline $\begin{array}{l}\qquad \text { Retrieval event (RE) } \\
\text { Imagine you have a friend who has a dog. You ask } \\
\text { him when he got it. He says he got it as a puppy } \\
\text { and he knows it was a Christmas gift, but he does } \\
\text { not remember the year. What could he do to } \\
\text { remember the year he got his dog? }\end{array}$ & 1 & $\begin{array}{l}\text { Look at some documents } \\
\text { Recruit human assistance } \\
\text { Use mathematical reasoning } \\
\text { Associate other details of the relevant } \\
\text { Christmas }\end{array}$ & $\begin{array}{c}\text { General }-/ \\
\text { Internal strategy }- \text { MAX }=2 \\
\text { External strategy }- \text { MAX }= \\
2\end{array}$ \\
\hline $\begin{array}{l}\text { Retroactive interference (RI) } \\
\text { One day, two friends go to a party and meet } 7 \\
\text { children they did not know before. After the party, } \\
\text { one of the two friends comes back home while the } \\
\text { other goes to play football. There, he meets } 6 \\
\text { children he did not know before. In the evening, } \\
\text { the children are asked by their parents for the } \\
\text { names of all the children they met at the party. } \\
\text { Who is going to remember better? The one who } \\
\text { came straight home or the one who played } \\
\text { football? Why? }\end{array}$ & 3 & $\begin{array}{l}\text { The child who went back home } \\
\text { The one who played football met more } \\
\text { children. He is more likely to mix up the } \\
\text { children's names. }\end{array}$ & $\begin{array}{l}\text { General - MAX = } 3 \\
\text { Internal strategy - / } \\
\text { External strategy - / }\end{array}$ \\
\hline Rote paraphrase (RP) & & In his own words & \\
\hline $\begin{array}{l}\text { There is a boy. His teacher has asked him to listen } \\
\text { to a story on a CD. He instructed him to pay } \\
\text { attention to it because he will have to tell the } \\
\text { whole story to the class later. How do you think it } \\
\text { will be easier for the boy to tell the story later: } \\
\text { word for word or in his own words? Why? What } \\
\text { would you do if you wanted to learn a story word } \\
\text { for word? What would you do if you wanted to } \\
\text { learn a story in your own words? }\end{array}$ & 1 & $\begin{array}{l}\text { Learning something by heart without } \\
\text { repetition is very hard. In our own words, we } \\
\text { just have to remember the important events } \\
\text { of the story. } \\
\text { Rehearse } \\
\text { Remember key events }\end{array}$ & $\begin{array}{c}\text { General }-\mathrm{MAX}=2 \\
\text { Internal strategy }-\mathrm{MAX}=2 \\
\text { External strategy }-/\end{array}$ \\
\hline
\end{tabular}


Table 2

Factor Structure of the French-Adapted Metamemory Scale

\begin{tabular}{|c|c|c|c|c|c|c|c|c|c|c|}
\hline & $\begin{array}{c}\text { PO- } \\
\text { External }\end{array}$ & $\begin{array}{l}\text { PO- } \\
\text { Internal }\end{array}$ & $\begin{array}{c}\text { ID- } \\
\text { General }\end{array}$ & $\begin{array}{l}\text { ID- } \\
\text { Internal }\end{array}$ & $\begin{array}{c}\text { ID- } \\
\text { External }\end{array}$ & $\begin{array}{c}\text { RE- } \\
\text { Internal }\end{array}$ & $\begin{array}{c}\text { RE- } \\
\text { External }\end{array}$ & $\begin{array}{c}\text { RI- } \\
\text { General }\end{array}$ & $\begin{array}{c}\text { PC- } \\
\text { General }\end{array}$ & $\begin{array}{c}\text { PC- } \\
\text { Internal }\end{array}$ \\
\hline \multicolumn{11}{|l|}{ Factor Loading } \\
\hline Internal strategy & - & .45 & - & .90 & - & .82 & - & - & - & .89 \\
\hline External strategy & .77 & - & - & - & .91 & - & .76 & - & - & - \\
\hline General & - & - & .46 & - & - & - & - & .71 & .73 & - \\
\hline
\end{tabular}

Note. $\mathrm{PO}=$ preparation object; $\mathrm{ID}$ = immediate delay; $\mathrm{RE}$ = retrieval event; $\mathrm{RI}$ = retroactive interference; $\mathrm{RP}=$ rote paraphrase. 
Page 30

Table 3

Correlations between Language and Metamemory Item Scores

\begin{tabular}{lc}
\hline & PPVT-R \\
\hline PO-External & -.086 \\
PO-Internal & -.051 \\
ID-General & $.192^{*}$ \\
ID-Internal & .061 \\
ID-External & .13 \\
RE-Internal & -.038 \\
RE-External & .126 \\
RI-General & .05 \\
PC-General & .052 \\
PC-Internal & \\
\hline p c.05 & \\
\hline
\end{tabular}

Note. $\mathrm{PO}=$ preparation object; $\mathrm{ID}=$ immediate delay; $\mathrm{RE}=$ retrieval event; $\mathrm{RI}=$ retroactive interference; $\mathrm{RP}=$ rote paraphrase. 
Page 31

Table 4

Scores (Means and Standard Deviations) on Memory and Metamemory Tasks by Age Group

\begin{tabular}{lllllll}
\hline & All $(\mathrm{n}=128)$ & 4 years $(\mathrm{n}=32)$ & 6 years $(\mathrm{n}=32)$ & 9 years $(\mathrm{n}=32)$ & 11 years $(\mathrm{n}=32)$ & $\mathrm{F}$ \\
\hline Metamemory scale & $9.03(4.43)$ & $4.06(2.73)$ & $7.16(2.49)$ & $11.87(2.37)$ & $13.03(2.66)$ & $84.70^{*}$ \\
Internal strategies & $1.83(1.61)$ & $0.31(0.78)$ & $1.22(1.24)$ & $2.69(1.23)$ & $3.09(1.33)$ & $39.45^{*}$ \\
External strategies & $3.67(1.62)$ & $1.91(1.33)$ & $3.34(1.12)$ & $4.62(1.04)$ & $4.81(1.00)$ & $45.41^{*}$ \\
General knowledge & $3.53(1.92)$ & $1.84(1.22)$ & $2.59(1.50)$ & $4.56(1.14)$ & $5.12(1.34)$ & $41.55^{*}$ \\
ARC - semantic & $0.47(0.35)$ & $0.34(0.62)$ & $0.65(0.23)$ & $0.48(0.10)$ & $0.40(0.09)$ & $4.99^{*}$ \\
ARC - serial & $0.37(0.11)$ & $0.43(0.16)$ & $0.37(0.09)$ & $0.34(0.06)$ & $0.36(0.07)$ & $4.79^{*}$ \\
Free recall (2-minute) & $7.05(2.57)$ & $4.31(2.22)$ & $6.53(1.72)$ & $8.41(1.39)$ & $8.97(1.87)$ & $42.49^{*}$ \\
Free recall (20-minute) & $6.98(2.59)$ & $4.16(1.97)$ & $6.19(1.69)$ & $8.62(1.64)$ & $8.97(1.51)$ & $55.53^{*}$ \\
Cued recall (2-minute) & $6.54(2.88)$ & $3.22(1.91)$ & $5.62(1.86)$ & $8.41(1.52)$ & $8.91(1.71)$ & $72.27^{*}$ \\
Cued recall (20-minute) & $6.59(3.01)$ & $3.03(1.73)$ & $5.56(1.87)$ & $8.53(1.63)$ & $9.22(1.66)$ & $87.63^{*}$ \\
\hline *p < .01 & & & &
\end{tabular}


Page 32

Table 5

Hierarchical Regressions Accounting for each of the two composite memory scores

\begin{tabular}{|c|c|c|c|c|c|c|}
\hline & B & $\mathrm{SEb}$ & $\beta$ & $\mathrm{t}$ & $\mathrm{p}$ & $\Delta \mathrm{R}^{2}$ \\
\hline \multicolumn{7}{|l|}{ Recall (Free) } \\
\hline Age (months) & .01 & .003 & .50 & 5.12 & $<.001$ & .51 \\
\hline Metamemory (Total) & .06 & .021 & .30 & 3.06 & .002 & .07 \\
\hline \multicolumn{7}{|l|}{ Recall (Cued) } \\
\hline Age (months) & .01 & .003 & .54 & 5.63 & $<.001$ & .53 \\
\hline Metamemory (Total) & .05 & .02 & .27 & 2.82 & .005 & .06 \\
\hline \multicolumn{7}{|l|}{ Recall (Free) } \\
\hline Age (months) & .01 & .003 & .49 & 5.01 & $<.001$ & .52 \\
\hline Internal strategies & .10 & .05 & .17 & 2.09 & .04 & .04 \\
\hline External strategies & .06 & .05 & .11 & 1.29 & .20 & .01 \\
\hline General knowledge & .04 & .04 & .08 & 0.86 & .39 & .01 \\
\hline \multicolumn{7}{|l|}{ Recall (Cued) } \\
\hline Age (months) & .01 & .002 & .54 & 5.58 & .02 & .54 \\
\hline Internal strategies & .08 & .04 & .14 & 1.76 & .08 & .03 \\
\hline External strategies & .02 & .04 & .04 & 0.44 & .65 & .01 \\
\hline General knowledge & .06 & .04 & .13 & 1.54 & .13 & .01 \\
\hline \multicolumn{7}{|l|}{ Recall (Free) } \\
\hline Age (months) & .02 & .002 & .74 & 12.15 & $<.001$ & .53 \\
\hline ARC - semantic & .35 & .17 & .13 & 2.03 & .04 & .03 \\
\hline ARC - serial & -.11 & .59 & -.01 & 0.18 & .85 & .01 \\
\hline
\end{tabular}

